


\section{Integration of Renewables}

\section{Status and challenges in China}

The views expressed in this working paper are those of the author and do not necessarily reflect the views or policy of the International Energy Agency (IEA) Secretariat or of its individual member countries. This paper is a work in progress, designed to elicit comments and further debate; thus, comments are welcome, directed to the author at: kat.cheung@iea.org

International Energy Agency

Kat Cheung 
The International Energy Agency (IEA), an autonomous agency, was established in November 1974. Its primary mandate was - and is - two-fold: to promote energy security amongst its member countries through collective response to physical disruptions in oil supply, and provide authoritative research and analysis on ways to ensure reliable, affordable and clean energy for its 28 member countries and beyond. The IEA carries out a comprehensive programme of energy co-operation among its member countries, each of which is obliged to hold oil stocks equivalent to 90 days of its net imports. The Agency's aims include the following objectives:

- Secure member countries' access to reliable and ample supplies of all forms of energy; in particular, through maintaining effective emergency response capabilities in case of oil supply disruptions.

- Promote sustainable energy policies that spur economic growth and environmental protection in a global context - particularly in terms of reducing greenhouse-gas emissions that contribute to climate change.

- Improve transparency of international markets through collection and analysis of energy data.

- Support global collaboration on energy technology to secure future energy supplies and mitigate their environmental impact, including through improved energy

efficiency and development and deployment of low-carbon technologies.

Find solutions to global energy challenges through engagement and dialogue with non-member countries, industry, international organisations and other stakeholders.

IEA member countries:

\section{Austria}

Belgium

Canada

Czech Republic

\section{Denmark}

Finland

France

Germany

Greece

Hungary

Ireland

Italy

Japan

Korea (Republic of)

Luxembourg

Netherlands

New Zealand

Norway

Poland

Portugal

(c) OECD/IEA, 2011

\section{International Energy Agency}

9 rue de la Fédération

75739 Paris Cedex 15, France

www.iea.org

Please note that this publication

is subject to specific restrictions

that limit its use and distribution.

The terms and conditions are available

online at www.iea.org/about/copyright.asp

Slovak Republic

Spain

Sweden

Switzerland

Turkey

United Kingdom

United States

The European Commission

also participates in

the work of the IEA. 


\section{Acknowledgement}

This publication was prepared by the International Energy Agency's Energy Technology Policy Division. Kat Cheung was the lead author; Bo Diczfalusy, Director of Sustainable Energy Policy and Technology, and Peter Taylor, Head of Energy Technology Policy Division, provided leadership throughout its development. Many other IEA colleagues provided valuable contributions, in particular Robert Arnot, Hugo Chandler, Yuichi Ikeda, Tom Kerr, Steven Lee, Uwe Remme and Jonathan Sinton. Kevin Porter of Exeter Associates and Shi Jingli of National Development and Reform Committee Energy Research Institute (NDRC ERI) provided important inputs. This paper is partly a result of closer co-operation between IEA and China's NDRC ERI, especially in the areas of renewable energy and technology roadmaps. The IEA Chief Editor, Marilyn Smith, provided editorial guidance; Corinne Hayworth designed the cover pages and Anne Mayne developed the final layout.

For more information on this paper, contact:

Kat CHEUNG

IEA Energy Technology Policy Division

Tel: +33 (0)1 40576653

Email: kat.cheung@iea.org 



\section{Table of Contents}

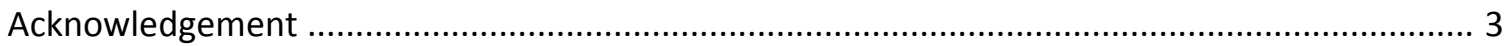

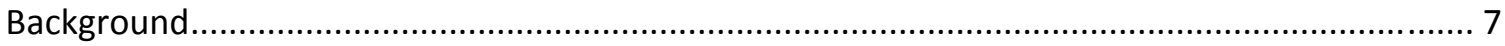

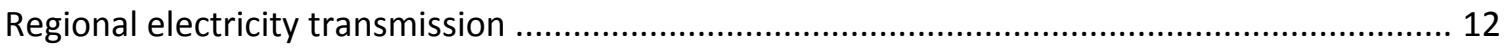

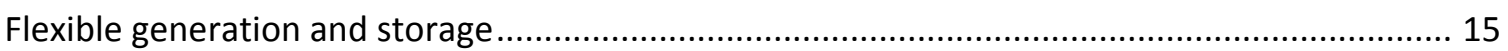

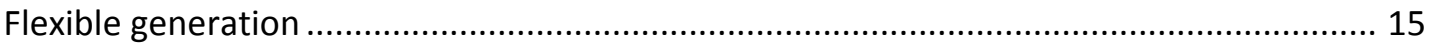

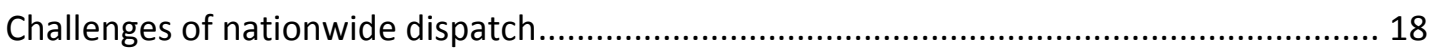

Testing a new approach to preferential dispatch ............................................................ 19

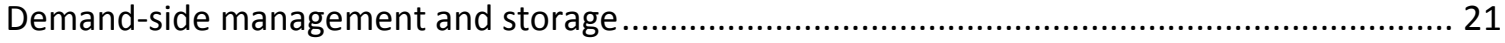

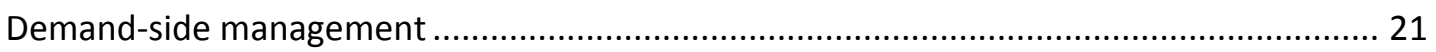

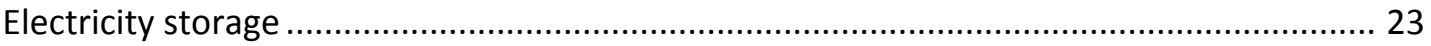

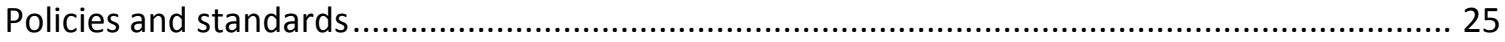

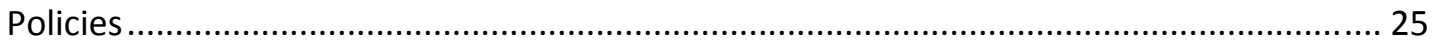

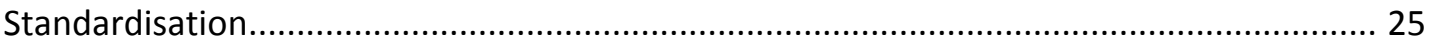

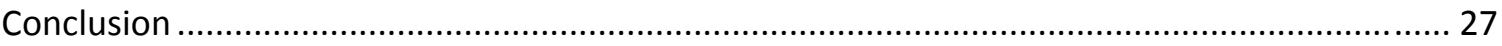

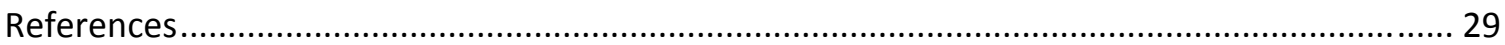

\section{List of figures}

Figure 1. Electricity consumption in China, 2000-35............................................................. 7

Figure 2. Electricity generation capacity and production in China, 2009 .................................... 8

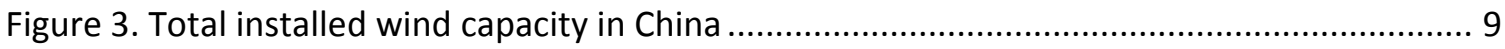

Figure 4. Current installed wind capacity by province 2009 (MW) .......................................... 10

Figure 5. Third national survey of onshore wind resources ...................................................... 11

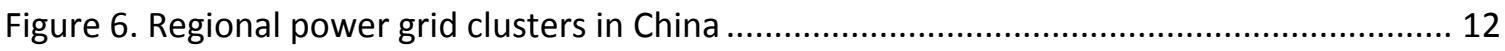

Figure 7. Planned interconnection of regional power grids in China.......................................... 14

Figure 8. Distribution of hydropower in China's six regional grids ........................................... 17

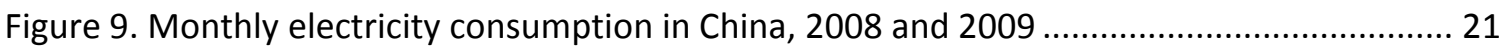

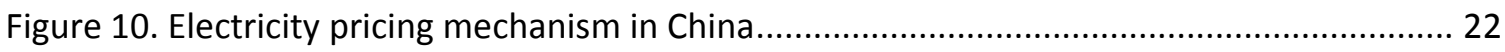

\section{List of tables}

Table 1. Power transmission grids: planned, under construction or operating ........................... 14

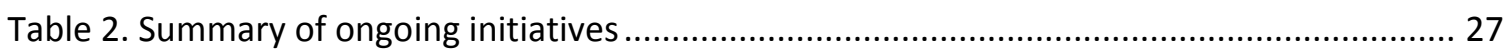

\section{List of boxes}

Box 1. Possible impacts of higher penetration of variable renewables on the power system ....... 9

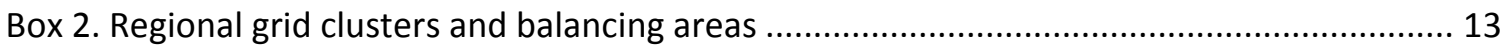

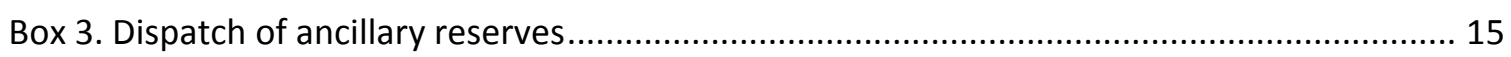

Box 4. How electricity trading plays a role: the case of Denmark.............................................. 19

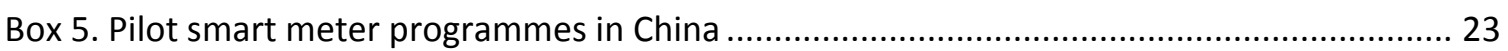





\section{Background}

The security of energy supply, including that of electricity, is a paramount issue in China - a country with a land area of 9.6 million $\mathrm{km}^{2}$, abundant natural resources and $14 \%$ of the world's population. In January 2008, power blackouts were recorded in 17 provinces in China, due to prolonged snow and icy weather. Power grids were damaged, and heavy snow blocked the transport of coal by rail to the east. In recent years, severe droughts have frequently hit the hydro-rich southern region of China, leaving millions without drinking water, while the generation of hydro-electricity was significantly reduced.

Security of electricity supply is an aspect of the broader notion of energy security. A range of issues - such as fuel supply, extreme weather and increasing variable renewable energy in the power mix, etc. - all have impacts on a country's ability to securely deliver electricity to its households and industry. For China, electricity security is increasingly a concern. Reliable and secure electricity supply is strongly linked to the Chinese government's fundamentals for policy making, notably social stability and economic growth.

This working paper will try to shed light on the country's efforts to integrate an increasing quantity of electricity from variable renewable sources in the power systems. Its focus is on wind power, as capacity has increased rapidly and is projected to continue to increase significantly.

China's economy ran at a double-digit growth rate (as measured by the percentage increase in gross domestic product) from 2003 to 2008 when the global financial crisis hit, and the country came out strongly from the crisis (ADB, 2010). In parallel to this impressive growth, total primary energy consumption increased from 776 million tonnes of oil equivalent (Mtoe) in 2000 to 2164 Mtoe in 2009, reflecting a compound annual growth rate in excess of $8 \%$ (NBS, 2010). In the same period, electricity consumption rose to 3643 terawatt hours (TWh) in 2009, up 6\% compared to 2008 and increasing by a factor of 3.4 times since 2000 (CEC, 2010). The IEA estimates that China's electricity demand will almost triple to 9594 TWh by 2035, with an average growth rate of $5.3 \%$ (Figure 1) (IEA, 2010a).

Figure 1. Electricity consumption in China, 2000-35

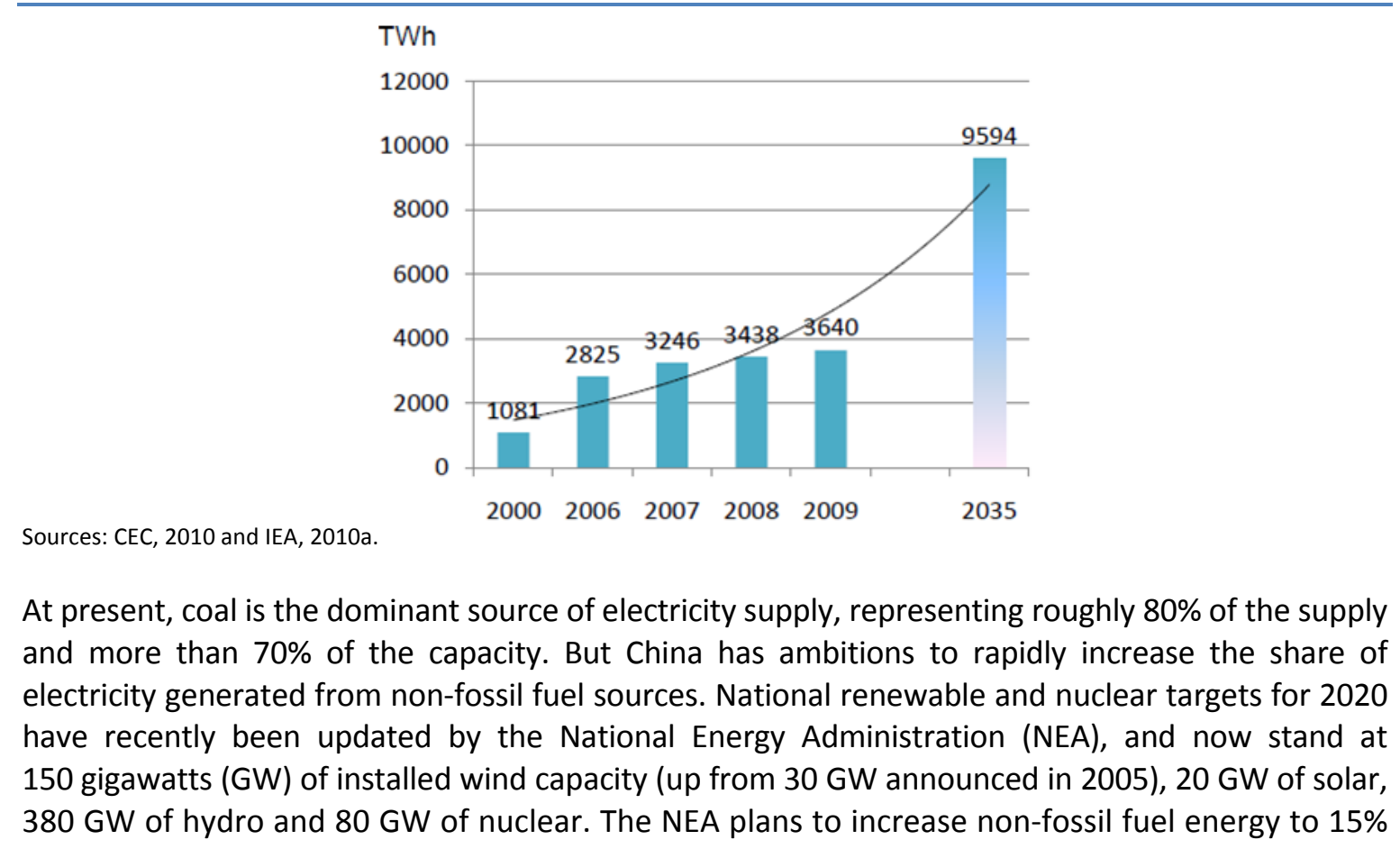


of the total primary energy consumption by 2020 . These targets are in addition to its announced target of $40 \%$ to $45 \%$ reduction in energy intensity by 2020 . This implies that wind energy should increase an average of $12.5 \mathrm{GW}$ and solar of close to $2 \mathrm{GW}$ each year through to 2020.

Almost non-existent until a few years ago, installed renewable electricity ${ }^{1}$ capacity (excluding hydro) in China has doubled every year since 2005. Much of this growth is due to the enactment

Page $\mid 8$ of the Renewable Energy Law in the same year, which gave a strong signal and long-term certainty to industry. In 2009, the total electricity generation capacity in China amounted to $874 \mathrm{GW}$, of which thermal power supply accounts for $74.6 \%$, hydro for $22.5 \%$ and (gridconnected) wind for $1.8 \%$ (Figure 2).

Figure 2. Electricity generation capacity and production in China, 2009

Electricity Production 3663 TWh

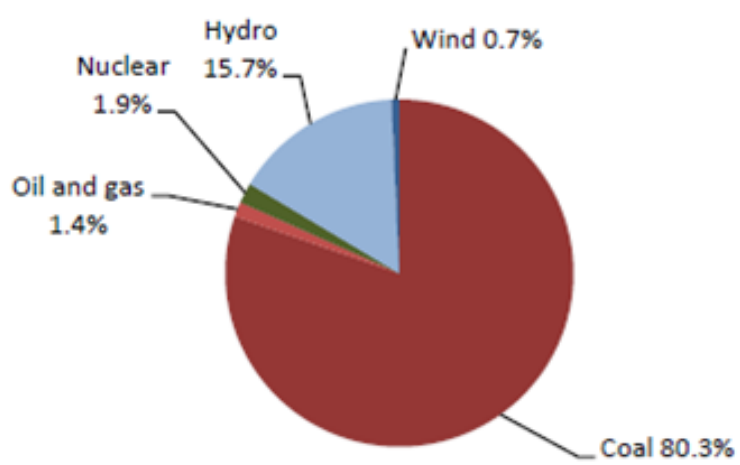

Installed Capacity 874 GW

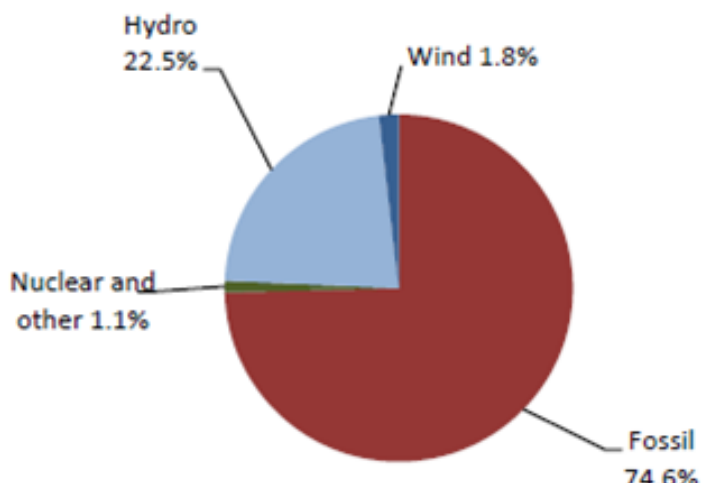

\begin{tabular}{|l|c|c|c|}
\hline & $\begin{array}{c}\text { Total installed capacity } \\
\text { by } \mathbf{2 0 0 9}(\mathrm{GW})\end{array}$ & $\begin{array}{c}\text { Total electricity } \\
\text { production (TWh) }\end{array}$ & $\begin{array}{c}\text { Share of the total } \\
\text { electricity production (\%) }\end{array}$ \\
\hline Hydro & 196.8 & 574.7 & 15.7 \\
\hline Wind (grid connected) & 16.1 & 26.9 & 0.7 \\
\hline Solar & 0.3 & 0.5 & - \\
\hline Biomass & 4.0 & 20.0 & 0.6 \\
\hline Total & 217.3 & 620.6 & 17.0 \\
\hline
\end{tabular}

Sources: MIIT, 2010 and CEC, 2010.

Although the share of renewables in China is small and the annual increase of coal power capacity surpasses that of renewables by wide margin, the magnitude and speed of renewables growth is significant. The installed wind capacity increased more than tenfold from $28 \mathrm{MW}$ in 1996 to 42 GW by the end of 2010 according to preliminary data obtained (Figure 3) (FT, 2010).

In the western province of Gansu, a wind farm project of $3.8 \mathrm{GW}$ was built in 2010 constituting the first phase in a $10 \mathrm{GW}$ project. This is the first of seven planned $10 \mathrm{GW}$ mega wind farms in China. The Chinese government is pursuing wind energy development with the same vigour they showed for hydro. Their approach is increasingly known as "Three Gorges on the Land" with reference to a massive scale of development comparable to that of the Three Gorges Dam. In 2009, China added $13 \mathrm{GW}$ to total capacity (of which $5.5 \mathrm{GW}$ was installed in Inner Mongolia) and was on par with Germany as the world's second-largest installed capacity. Chinese capacity surpassed that of the United States in 2010, and the country became the world's largest wind power capacity holder.

\footnotetext{
${ }^{1}$ Although hydro is included in the Renewable Energy Law, it is considered more as a conventional power generation source. Discussion of renewables here includes only variable renewable energy, i.e. wind and solar.
} 
Figure 3. Total installed wind capacity in China

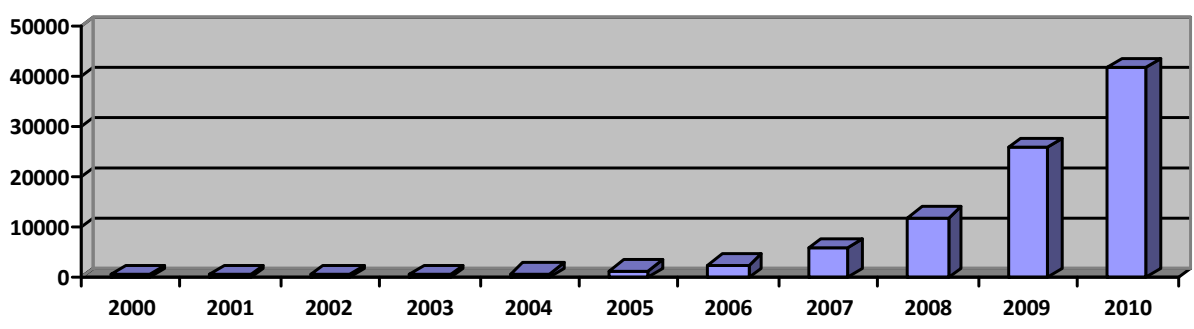

Sources: GWEC, 2009 and Interfax, 2010.

Variable renewables when connected to the grid, especially in large shares, pose challenges to power system operators (Box 1). Smooth integration of variable renewables needs to draw on a portfolio of solutions, including generation, interconnections, transmission and distribution, storage, and demand-side management. Geographic characteristics of a specific country influence the appropriate combination of solutions.

Box 1. Possible impacts of higher penetration of variable renewables on the power system

Electricity cannot be stored on a massive scale in an economic way. Thus, system operators must balance the power supply and demand at all times in order to maintain system stability and power quality. Major mismatches or interruptions could lead to breakdown of a power system and blackout of a power area.

Conventional power generation fired by coal, oil, gas or nuclear provides steady and predictable feedin to the grids. Their output can be scheduled. This is also true for some renewable energy such as hydro and biomass power generation.

Variable renewables refer to those energy sources such as wind and solar, for which power output is intermittent and cannot be accurately and completely predicted or scheduled. An increasing amount of variable renewables feeding to the grids poses challenges to system operators who have to deal with higher unpredictability of net load variability and to balance the fluctuations.

Measures to smooth out the variability include (but are not limited to) enlarging the balancing area, load shifting, building in more flexibility in the generation portfolio, etc. The impacts of higher integration of variable renewables vary according to the type of technology and the level of penetration. Thus, key questions are often how (and how well) the integration of variable renewables is managed and at what costs?

In China, long-distance power transmission is often cited as an important factor in power sector decision making by the government. Of particular concern is that the concentration of wind farms build-out in the north and northeast (where the wind resources are among the richest) is a great distance from main demand centres (Figure 4).

In western Inner Mongolia, wind already provided 6 TWh of electricity in 2009, about $6 \%$ of the total electricity generated in this region (EEO, 2010). Local demand is often lower than the supply. When the wind is blowing, surplus power is exported by transmitting electricity generated to adjacent grids. However, as only two 500-kV transmission lines are currently connected to the adjacent North regional grid, passing on surplus is possible only when the additional amount of electricity is still relatively low. In the winter, when district heating from combined heat and power (CHP) plants must be assured, power generated from wind farms is often severely curtailed in the region - sometimes to levels as low as 20\% (BNEF, 2010b). 


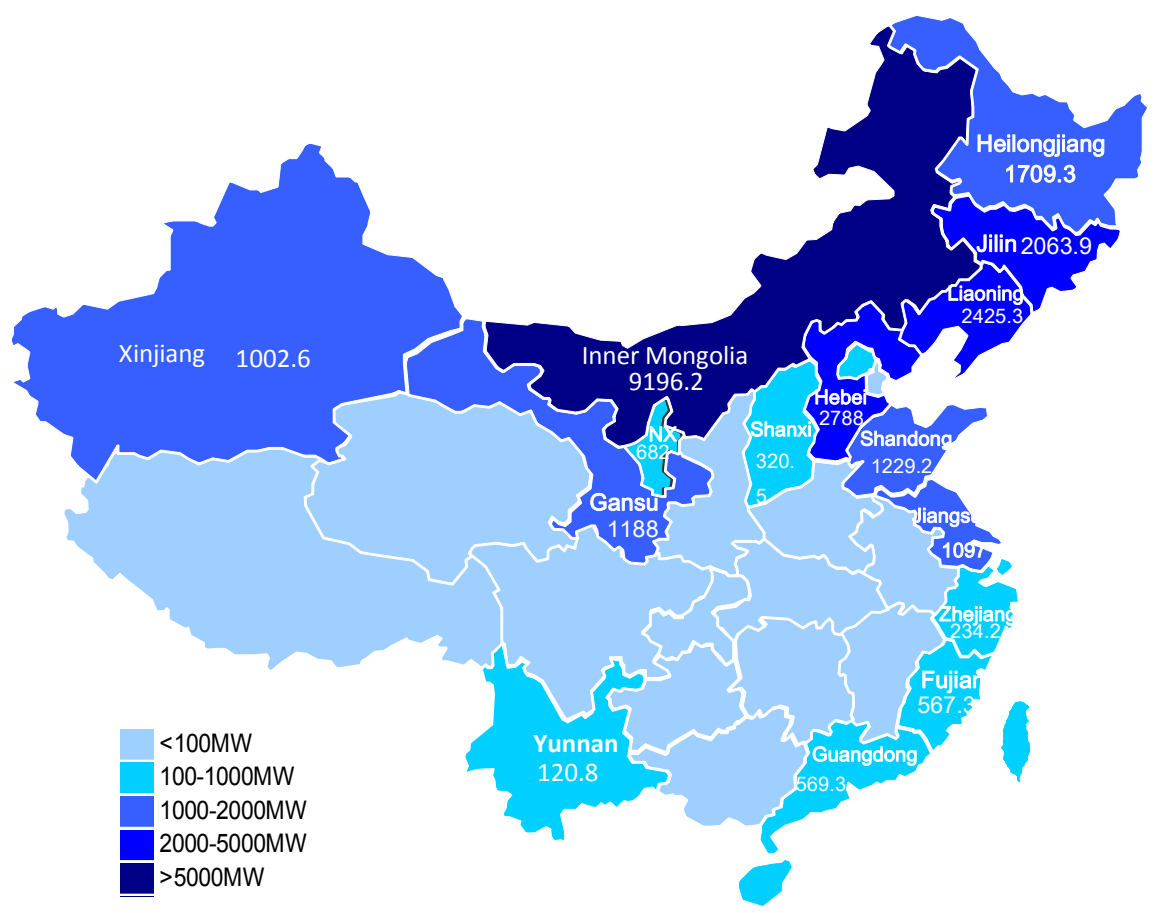

Source: CWEA, 2010.

The total wind capacity in Inner Mongolia is estimated to have doubled again in 2010 (pending the release of official data). Thus, for power system operators, the challenge of integrating a rapidly increasing penetration of variable renewables is imminent. On the supply side, wind farm developers will face stiff competition for currently inadequate or slow connections to local and regional grids. This is particularly challenging in that even when existing wind farms are connected, grid operators frequently curtail wind power and wind farms run insufficient hours to remain economically viable.

A recent national wind resources survey conducted by the China Meteorological Administration (CMA), shows $2380 \mathrm{GW}$ of onshore and $200 \mathrm{GW}$ offshore potential - some 100 times the current installed capacity (Figure 5). The survey confirms a further concentration of mega wind farms in northern China in the future. The geographic mismatch of electricity demand and supply in China will be increasingly evident.

Regional grid companies currently apply a three-step approach to electricity from variable sources. First, they try to accommodate the variable supply. If accommodation cannot be easily managed, they will instead curtail the surplus. The third option of transmitting the surplus to neighbouring power systems is severely restricted due to a lack of inter-regional grid connections.

This approach needs also to be understood against the background of China's current energy mix and growing energy demand. In 2009, coal supplied $80 \%$ of the electricity generated (Mi, 2010), and many analysts predict it will remain the main source of electricity for the medium to long term. At present, $112 \mathrm{GW}$ of coal-fired power plants are under construction in China (IEA, 2009). In contrast to the United States, Japan or other developed countries where energy demand has largely stabilised, China needs an inexpensive and reliable energy supply to fuel the continued economic growth led by the manufacturing industry and exports. Guaranteeing coal power generation and transmission is therefore a top priority. 
Figure 5. Third national survey of onshore wind resources

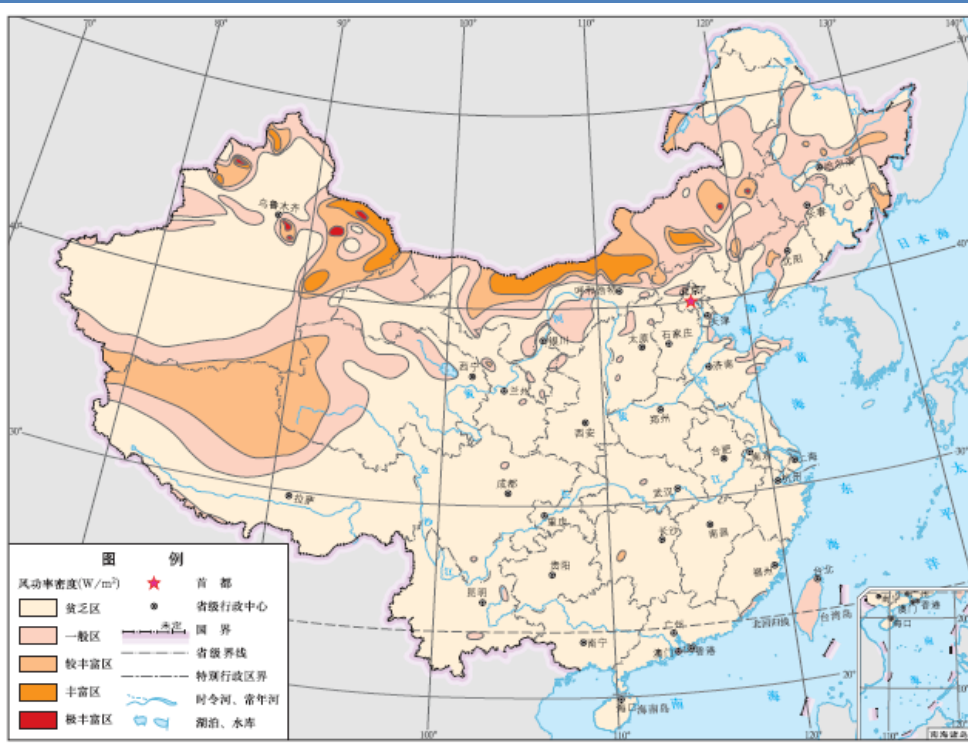

\begin{tabular}{|c|c|c|c|}
\hline $\begin{array}{c}\text { Height above } \\
\text { ground }\end{array}$ & $\begin{array}{c}\text { Wind Class IV } \\
\mathbf{4 0 0} \mathbf{W} / \mathbf{m}^{\mathbf{2}}\end{array}$ & $\begin{array}{c}\text { Wind Class III } \\
\mathbf{3 0 0} \mathbf{W / \mathbf { m } ^ { \mathbf { 2 } }}\end{array}$ & $\begin{array}{c}\text { Wind Class II } \\
\mathbf{2 0 0} \mathbf{W} / \mathbf{m}^{\mathbf{2}}\end{array}$ \\
\hline $50 \mathrm{~m}$ & $1130 \mathrm{GW}$ & $\mathbf{2 3 8 0 \mathrm { GW }}$ & $3940 \mathrm{GW}$ \\
\hline $70 \mathrm{~m}$ & $1510 \mathrm{GW}$ & $2850 \mathrm{GW}$ & $4790 \mathrm{GW}$ \\
\hline $110 \mathrm{~m}$ & $2310 \mathrm{GW}$ & $3800 \mathrm{GW}$ & $5730 \mathrm{GW}$ \\
\hline
\end{tabular}

Source: CMA, 2010.

Some signs indicate that China is taking steps to promote a new approach in which greater effort is made to accommodate and transmit more renewable electricity, before curtailing it. Recent expansion of long-distance, cross-regional power transmission is definitely part of the strategy, but the Chinese government is also taking actions in other areas. More flexibility is being built into its power generation portfolio. Measures are being taken to promote a more interactive demand response. Targeted policy making and technical standards setting are helping to provide the right signals to stakeholders. All these increase the potential of China's capacity to accommodate a higher penetration of variable renewables.

This paper gives an overview of major developments and initiatives of integrating renewables in China, looking at all four of these areas:

- Regional electricity transmission

- Flexible generation

- Demand-side management and storage

- Policies and standards

Some of these areas are inevitably intertwined with the nature and design of China's electricity power market and pricing mechanism, which will have an impact on the effectiveness of the country's targeted efforts to integrate larger shares of renewables. 


\section{Regional electricity transmission}

China does not have a unified national electricity grid. Its current grid system is fragmented into six regional power grid clusters, all of which operate rather independently (Figure 6). The State Grid Corporation of China (SGCC) manages four of the clusters (the East, Central, Northwest,

Page | 12 Northeast grids) as well as part of the North grid (specifically the eastern part of the Inner Mongolia grid). This network covers 26 provinces. The western part of the Inner Mongolia grid is managed by an independent company (a black indicative line in Figure 6 marks the division of management of the Inner Mongolia grid). The South grid is managed by the China Southern Grid Company (CSGC). Inter-regional interconnections are weak. Cross-regional trade of electricity amounted to 158 TWh in 2009 , representing only $4 \%$ of the total electricity production.

Figure 6. Regional power grid clusters in China

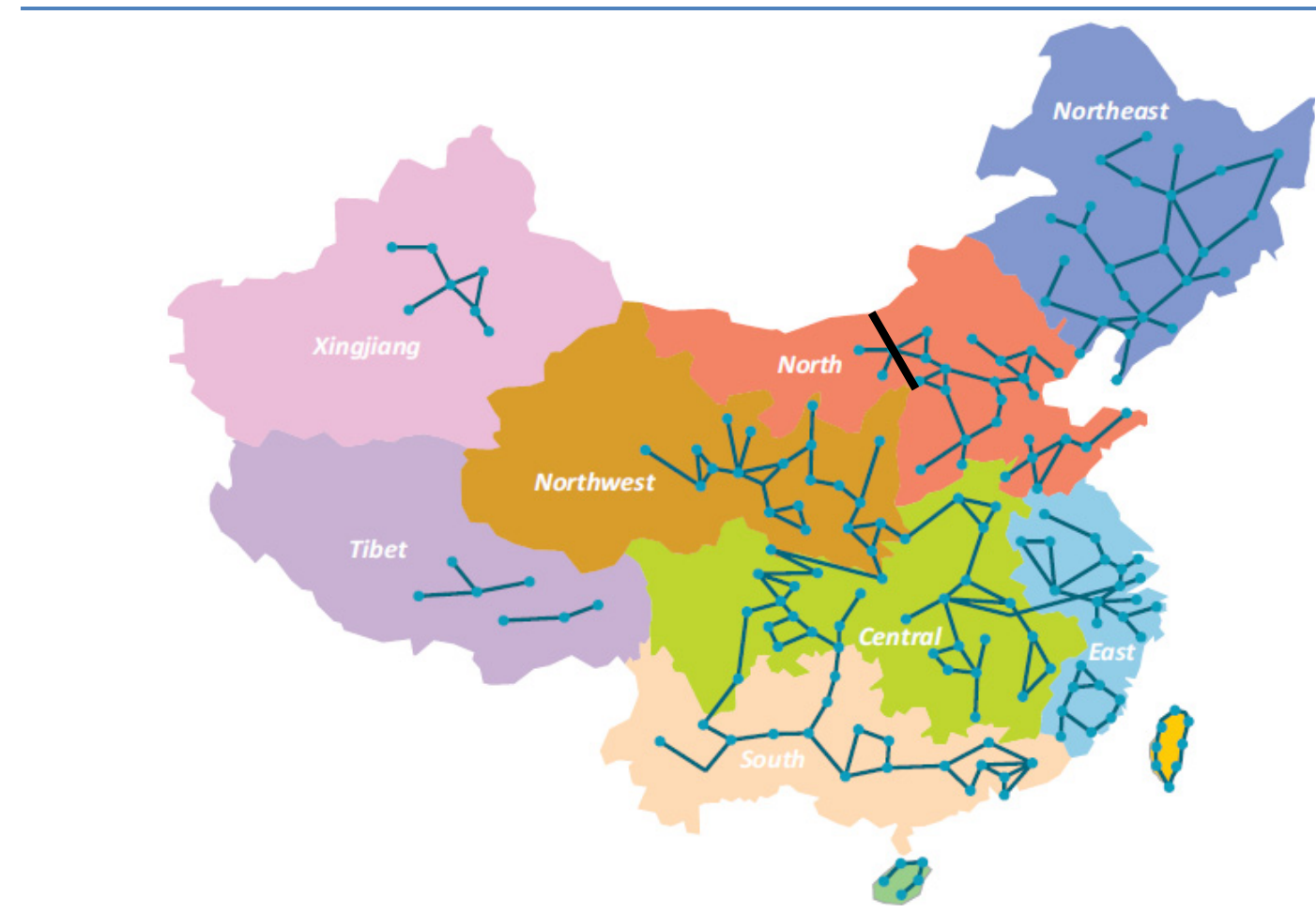

Source: Wang, 2009.

Capacity to balance power fluctuations that arise from integrating a higher proportion of variable renewables can be enhanced when power balancing is managed across a larger balancing area. Studies of systems integration of renewables confirm the smoothing effect of connecting separate but contiguous power areas (Chandler, 2009). The variable power output of individual wind farms, for example, is reduced by connecting a wider geographical spread of variable sources. The higher the aggregate generation, the lower will be the net variability.

To smooth out the load variability in a power system, grid companies in China have come to realise that it is imperative to take two interrelated measures:

- Overcome the geographic mismatch of demand and supply by building additional power transmission lines to handle the transmission of larger quantities of electricity from variable sources;

- Strengthen the interconnections between regional grids. 
With a larger balancing area, more ancillary services become available to handle increased net load variability. Load changes could be potentially met nationally instead of regionally or provincially. This is an important step towards a national grid.

Box 2. Regional grid clusters and balancing areas

Currently, in each of China's six regional grid clusters, balancing of supply and demand takes place essentially at the provincial level. One province represents one balancing area. Thus, the SGCC's jurisdiction of 26 provinces covers 26 balancing areas. Trading of power takes place both among provinces and among grid regions (Figure below). While cross-regional electricity trade remains extremely limited, inter-provincial electricity imports and exports within a grid cluster show more dynamism. In 2009, total electricity traded stood at $532 \mathrm{TWh}, 13 \%$ more than the previous year (Chang and Dayu, 2010) and 14\% of the total electricity generation in China. Of the total traded amount, cross-regional trade of electricity in the same year was only $158 \mathrm{TWh}$.

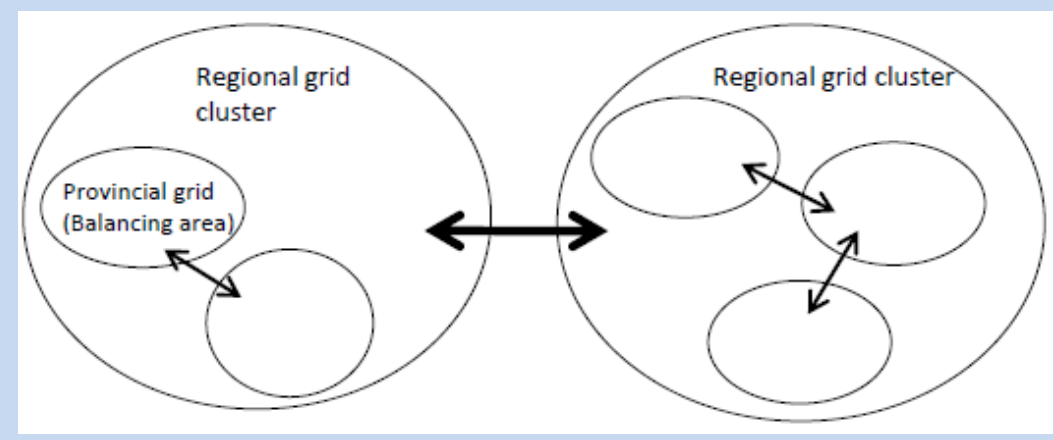

In March 2010, Premier Wen Jiabao addressed the National People's Congress and outlined a plan to build a "unified strong and smart grid" system nationwide by 2020 , which should incorporate energy supplies from various sources. Large-scale smart grid construction is set to be included in the $12^{\text {th }}$ Five-Year Plan. SGCC has a three-phase plan for a smart grid system that has an ultra-high-voltage (UHV) network at its core and will require a total investment of around RMB 270 billion (USD 40 billion) by 2020 (China Energy News, 2010a). The first step is to accelerate the construction of UHV transmission networks nationwide. By 2020, the basic framework for smart grid operational control and interaction should have been upgraded to form a unified, strong and smart grid system.

SGCC, together with the CSGC, has launched an extensive expansion of transmission grids nationwide. In January 2009, they put into commercial operation a $1000-k V$ UHV AC power line (Shanxi - Hubei); in June 2009, they added a 800-kV DC line (Yunan - Guangdong). SGCC started three new UHV AC power lines in 2009 connecting Xi'men and Nanjing, Sichuan and Shanghai, and western Inner Mongolia and Shangdong (China Energy News, 2010a). These lines will form the backbone "three horizontal, three vertical" UHV AC transmission lines, which should be constructed by 2015 according to the SGCC. In 2009, $2078 \mathrm{~km}$ of UHV transmission lines were added and state investment in the power transmission system exceeded that of new plant construction for the first time, at RMB 371 billion (USD 55 billion) - some $50.9 \%$ of the RMB 756 billion (USD 112 billion) total investment in the power sector (Zhang, 2010). Of the RMB 371 billion, RMB 18.8 billion (USD 2.8 billion) is invested in UHV transmission power lines.

China's new-found enthusiasm for smart grid has its roots. Existing UHV lines transmit large quantities of electricity over long distances with less power losses than the more commonly used 500-kv lines. This is in line with the government's energy conservation and emission reduction plans. According to SGCC's own estimation, a $1100-\mathrm{kv}$ UHV line can transmit up to four times more electricity than a 500-kV line, with only $1 / 16$ of the power loss (SGCC, 2010). 
Table 1. Power transmission grids: planned, under construction or operating

\begin{tabular}{|l|l|l|}
\hline UHV & Destinations & Status \\
\hline DC line & Yunan - Guangdong & In operation since June 2009 \\
\hline DC line & Xiang Jiaba - Shanghai & In operation since July 2010 \\
\hline DC line & Sichuan - southern Jiangsu Province (Shanghai) & Under construction \\
\hline DC line & Jinping - Sunan & Under construction \\
\hline AC line & Shanxi - Hubei & In operation since Jan 2009 \\
\hline AC line & Sichuan - Shanghai & Under construction \\
\hline AC line & Xi'men - Nanjing & Planned \\
\hline AC line & Western Inner Mongolia - Shangdong via Beijing & Planned \\
\hline
\end{tabular}

In addition, as mentioned before, non-variable power generation from thermal will still dominate China's energy mix in the medium and long run, and hydro is the single largest contributor of non-fossil fuel power generation. But large-scale coal mines and hydro stations are located equally far from demand centers in the east. Inner Mongolia, for example, holds one of the largest coal reserves in China. The UHV transmission lines could help alleviate the logistical bottleneck of coal transportation and secure electricity supply.

Figure 7. Planned interconnection of regional power grids in China

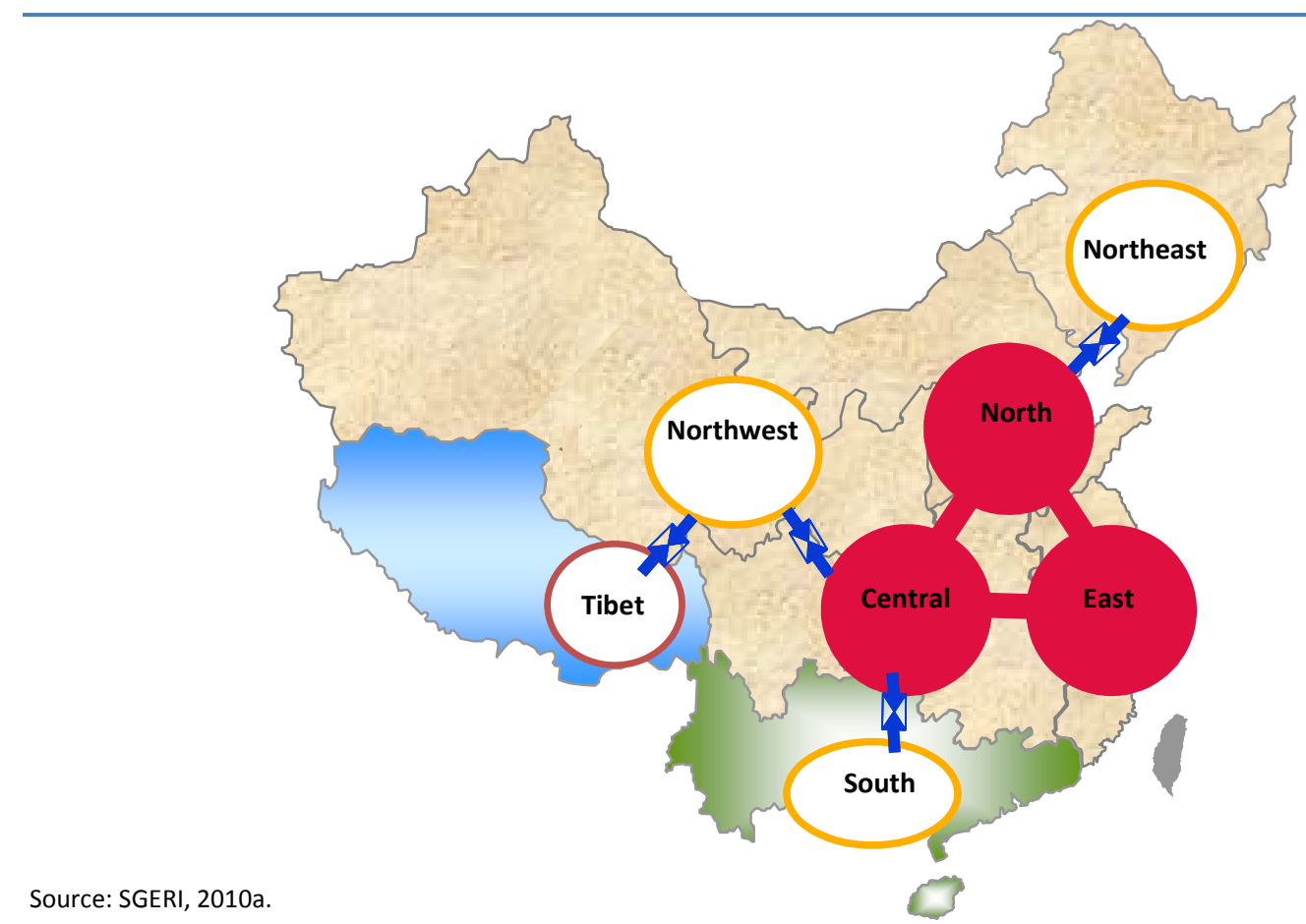

At the receiving end, to cope with the large quantity of electricity transmitted to the east, enhanced interconnections of regional grids are needed to handle the influx. To avoid congestion and potential damage to individual grids in case of major power fluctuations, SGCC is planning to significantly strengthen the interconnection of its three regional grids in the east, central and south of the country (Figure 7). In 2009, cross-regional trade of electricity is $11.4 \%$ higher than the previous year and totalled at 158 TWh (Zhang, 2010). 


\section{Flexible generation and storage}

\section{Flexible generation}

The intermittent nature and lower capacity factor of wind energy creates a need to ensure that the generation portfolio has flexible and fast-response ancillary services that can ramp electricity up or down in response to supply fluctuations. ${ }^{2}$ Many factors affect the choice of dispatchable generation including the unit's start-up/shut-down time, ramp rate, availability and costeffectiveness in a balancing area. Depending on how quickly it can ramp and other conditions, a generating plant can be used as primary (frequency-response), secondary (spinning and nonspinning) or tertiary (replacement) reserves (Box 3) (IEA RETD, 2010).

\section{Box 3. Dispatch of ancillary reserves}

A system operator's responsibility to provide uninterrupted supply of electricity entails the need to balance power fluctuations and ensure power quality at all times - including during scheduled or unforeseeable interruptions in a grid-connected power area.

The duration of power fluctuations can range between milliseconds to a few hours to a few days. To cope with all scenarios, the system operator must have a range of ancillary reserves in the generation portfolio to maintain system stability, regulation, load following and to prepare for the worst-case scenario.

Scheduling and dispatch of ancillary reserves is a complicated exercise. Ancillary reserves are generally divided into three categories according to how quickly they can ramp up or down its production to meet the demand. (Porter et al., 2009 and Porter, 2010).

- Frequency response reserves: Primary generating units that are usually online and synchronised. They can ramp up or down production very quickly (within a few seconds to minutes) to respond to frequency disturbances.

- Spinning and non-spinning reserves: Secondary generating units may or may not be online but can ramp up or down within a relatively short timeframe (within 10 minutes to a few hours).

- Replacement reserves: Tertiary generating units that are usually offline; they require more time (an hours to a few days) to start up or shut down in response to load changes.

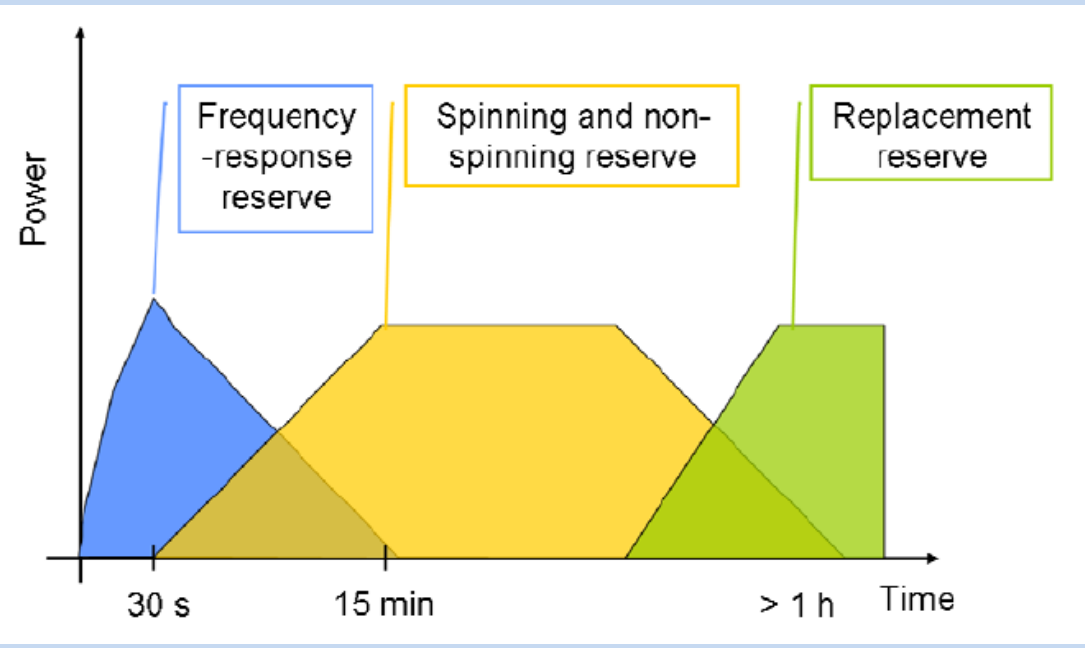

Source : IEA RETD, 2010.

\footnotetext{
${ }^{2}$ Capacity factor is one element in measuring the productivity of a wind turbine or any other power production facility. It compares the plant's actual production, over a given period of time, with the amount of power the plant would have produced if it had run at full capacity for the same amount of time. Wind plants have a capacity factor ranging from $25 \%$ to $40 \%$, lower than conventional plant with a factor from $40 \%$ to $80 \%$ (American Wind Energy Association).
} 
The amount of primary, secondary and tertiary reserves needed for a balancing area is casespecific. For a particular power system, a detailed integration study would need to determine system flexibility, as well as how many resources and reserves can be mobilised. Utilities and system operators consider elements such as the change velocity of the load (\% per min) and technical minimum load, etc. The scheduling and commitment of power generating units vary in each country or grid-connected balancing area dependent on the generation portfolio, availability of plants, market incentives and many other factors.

Relevant integration studies indicate that a higher penetration of renewables requires the availability of more ancillary units of longer timeframe, which is essentially the tertiary reserve (ENTSOE, 2010). Having more standby reserve adds to the operational costs for utilities. (In the case of China, these costs are not compensated through any market-based or priceincentivised mechanism.)

This section considers only the tertiary reserves of the longest timeframe, and examines the resource mix in China and the adequacy of generating and ancillary capacities nationwide. Coalfired power plants (large or small-scale), natural gas plants and hydro power plants (conventional and pumped hydro) together generated close to 97\% of China's total electricity in 2009.

\section{Coal-fired plants}

In China, coal-fired power plants account for more than two-thirds of the total installed power generation capacity. Coal plants (particularly smaller plants) are often readily available to be deployed to level out peaks and troughs in the power system. Their dispatch is, however, often outside economic or environmental considerations. Coal-fired power plants are less flexible in response to load changes because of their longer start-up/shut-down times and higher change velocity (due to thermal inertia). In addition, coal-fired plants run at a much lower efficiency when not operated at full capacity.

Smaller plants offer a more attractive option for flexible dispatching, but a key challenge is that such plants are becoming scarce. To improve overall plant efficiency and reduce emissions, the Chinese government has implemented initiatives to replace small coal-fired plants with larger plants (at least $600 \mathrm{MW}$ ). In 2009 alone, $26 \mathrm{GW}$ of small coal-fired plants were closed. The proportion of small plant capacity had decreased from 28\% in 2000 to 14\% in 2008 (Minchener, 2010). The move reduces the number of dispatchable smaller plants that system operators have in the generation portfolio.

\section{Natural gas plants}

Less than $1 \%$ of the total electricity generated in China comes from natural gas; the bulk of gas is used in residential space heating. This stagnant growth in gas power generation reflects concerns about the high price of gas and security of supply. Gas demand is increasingly met with the Central Asia-China (Turkmenistan) gas pipeline and imports of liquefied natural gas (LNG), which was delivered for the first time in 2006.

But gas plants are among the most flexible options to balance power system fluctuations, particularly plants operating on combined-cycle gas turbine. For natural gas power generation to become more competitive and play a greater role in power system balancing, electricity prices (which are currently heavily subsidised) need to be brought closer to market prices.

Independent of economic rationale, natural gas plants are set to increase. SGCC executives have outlined plans to add $43 \mathrm{GW}$ of natural gas stations to the corporation's fleet by 2015 . Half of the capacity will be installed near load centres in eastern China (BNEF, 2010a). 


\section{Hydropower plants}

Conventional and pumped hydro plants are among the optimum options to mitigate fluctuations in the power system. Both types of hydro plant can be started up or shut down quickly, without having major impact on the equipment's service life, and can operate at relatively low minimum load. Pumped hydro systems are particularly flexible; by discharging and charging water to/from upper and lower reservoirs, they can be brought into play during either peak or off-peak hours.

China has the highest installed hydro capacity in the world, and capacity has risen by over $10 \%$ in the past three years. Hydro is regarded as a natural resource that can contribute significantly to achieving the $15 \%$ non-fossil fuel target. The total hydro capacity is set to reach $380 \mathrm{GW}$ by 2020 (from $197 \mathrm{GW}$ in 2009) according to the NEA, an average annual increase of $16.5 \mathrm{GW}$.

Although power generation from conventional hydro plants is relatively stable compared to other renewables (e.g. wind or solar), seasonal factors influence production. In the drought season, which occurs in winter when wind blows hardest in the north, conventional hydro capacity is reduced and so is the dispatchable reserve. In Yunnan province, for instance, where $21 \mathrm{GW}$ of hydro power are installed, the supply difference between flood and drought seasons can be as large as $60 \mathrm{GWh}$ (CSG, 2005).

With allowance for these seasonal factors, conventional hydro stations in China are fully exploited to meet growing electricity demand and to balance variations in thermal plant production. However, the use of hydro to balance increased penetration of variable renewables is limited. At present, there is little spare hydro capacity left to mitigate increased net variability in the power system although more hydro capacity is coming online. Moreover, most (70\%) existing hydro stations are located in central and southern China where water resources are most abundant (SGERI, 2010b) (Figure 8), while wind resources are concentrated in the far north (Figure 4). Increasing the capacity of hydro to contribute to response to load changes, would require building/enhancing extensive power transmission lines to connect hydro in the south and wind in the north.

Figure 8. Distribution of hydropower in China's six regional grids

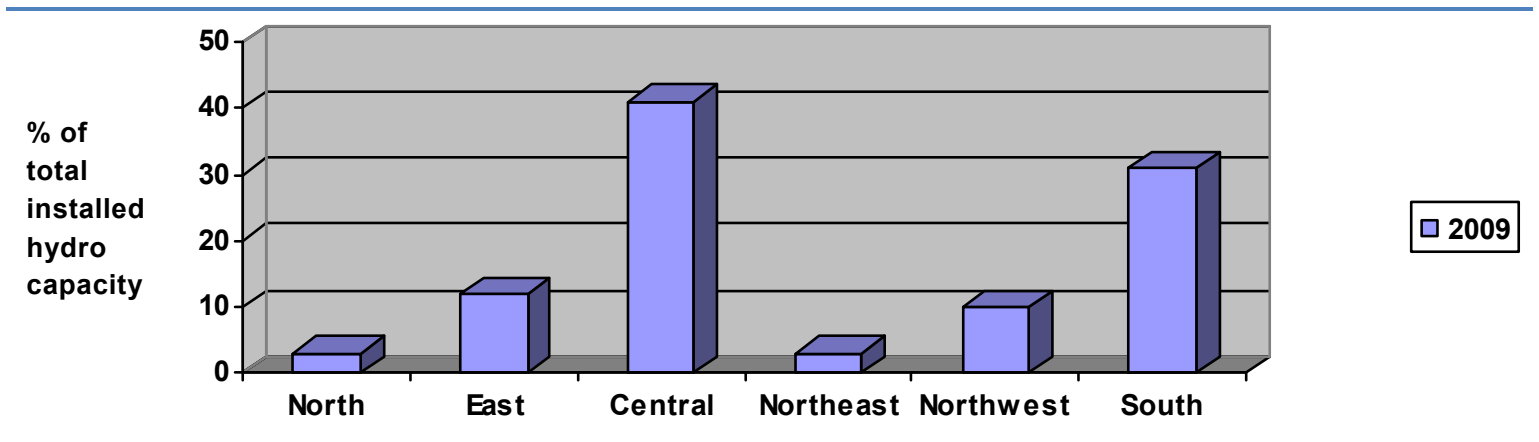

Source: SGERI, 2010.

Of the current installed hydro capacity (197 GW in 2009) in China, about $14 \mathrm{GW}$ are pumped hydro plants (Topcj, 2010), which have all the advantages of a conventional hydro plant and are less subject to seasonal conditions. With quick start-up times, pumped plants can ramp up from zero to full output in mere minutes. This makes them highly suitable to balance short-cycle load variation (Inage, 2009). Ideally, pumped hydro stations are installed close to the load centres and/or to large wind farms. 
In 2009 alone, the fleet of pumped hydro was expanded by $3.8 \mathrm{GW}$. China is exploring the possibility of adding more pumped hydro plants. SGCC estimates that China needs to install a total of $50 \mathrm{GW}$ to $60 \mathrm{GW}$ of pumped hydro stations by 2020. In Inner Mongolia, where wind capacity reached $9 \mathrm{GW}$ in 2009, construction of the first $4 \times 300 \mathrm{MW}$ pumped hydro station started in 2007; the plant is expected to be operational by 2012. Once finished, it will be connected with a 500-kV AC line to the regional grid of the west Inner Mongolia, and then onward to the UHV transmission line leading to the east.

\section{Challenges of nationwide dispatch}

The preceding section describes the status and some of the structural complications associated with China's power mix. These are complicated by administrative challenges and the rigidity of the electricity trading market, both of which may prove more difficult to overcome.

\section{Division of grid management}

Three independent grid companies - SGCC, CSGC and Western Inner Mongolia Grid Corporation - divide the management of power transmission and distribution systems in China. Each company is responsible for its own profit and loss. As a result, there is little incentive for intercompany co-operation. For example, there is little motivation for SGCC to bridge the transmission gap between its power area and that of the Western Inner Mongolia Grid Corporation (WIMGC), where most of the new wind farms have been installed. Likewise, it is a challenge for SGCC and CSGC to work together to take advantage of the flexible hydro power in the south.

Yet these three companies are collectively responsible for achieving targets set by top administration of the Chinese government - including integration of the ever-increasing share of variable renewables. Although centralised planning is the norm in China, regions and even stateowned companies have significant leeway when it comes to implementing policies and targets.

\section{Electricity trading market}

Drawing on available generating resources nationwide, current electricity trading practices in China are a key obstacle. Unless altered, trading practices will remain problematic even when new grids are constructed and long-distance electricity transmission realised. At present, more than $80 \%$ of the electricity trading between regions and provinces is governed by long-term contracts, under which both the quantity and prices of electricity traded are agreed to yearly based on multi-year demand and supply forecast. These negotiations are carried out among the central government, concerned provincial governments and the grid companies.

Only a small portion of electricity can be traded in the spot market (less than $20 \%$ of total electricity traded, which is $14 \%$ of total electricity generated in 2009) (Chang and Dayu, 2010). The amount is strictly limited and is usually reserved in cases of emergency. The majority of the electricity trading takes place based on yearly agreements among provinces. Actual trading (both the amount and timing) is reviewed weekly or monthly. This practice makes the power market extremely rigid: the tradable amount is capped and prices are fixed while the demand and export capacity of a province often evolve with time. It sometimes happens that an electricity-importing province has developed enough generation capacity over the year to meet demand, but must still receive electricity because of a prior agreement. As a result, the province must sell the surplus capacity to another region by significantly lower its export prices. 
Despite the rigid power market, system operators in a given province can adjust the capacity of their generation fleet to accommodate sudden influx of electricity coming from, for instance, a windy province. This is possible because power plants in China are allocated a more or less fixed number of operating hours according to the energy sources and technologies. For instance, coal plants operate for an average 5000 hours per year, hydro plants for 3500 hours, and wind plants for 2000 hours. Each provincial grid company is, therefore, responsible for ensuring that plants in its jurisdiction run sufficient allocated hours each year. This creates a situation in which a particular plant can be ordered to decrease its load at certain point of the year, and can be compensated for its lost hours later in the year.

Capability to ramp production exists. But fixed trading prices remove incentives for a system operator to receive surplus electricity that might tip the system off balance or force reduced load of a coal-dominant fleet, which is neither an economic nor an environmentally sound option. It is worth noting that utilities in China are not compensated for running their plants at less than full load or for maintaining ancillary services.

Given the lack of a market-based or price-incentivised mechanism, power system balancing is achieved because it has to be. This is very different from liberalised markets in countries such as Denmark, which has successfully integrated a much higher percentage of variable renewables in its power systems by fully exploiting the Nordic power market (Box 4).

Box 4. How electricity trading plays a role: the case of Denmark

Wind accounted for close to $20 \%$ of the electricity production in Denmark in 2008. This reflects high integration of Danish and other Nordic power transmission systems. Denmark's balancing resources come not only from within the country but also from, for instance, hydropower of Norway. Electricity production in Denmark can be traded (to hourly timescale) in the wider Nordic power market.

The zero fuel cost of wind means that power generated from wind has a lower marginal cost. When wind power is traded, it usually pushes down the electricity trading price at the spot market. The lower price provides incentive for other Nordic countries to purchase power from Denmark.

A few times per year, the power market becomes saturated and prices can drop to zero or even negative: when this occurs, utilities must pay to feed electricity onto the grid. In a fully liberalised power market, electricity trading prices vary with real-time demand and supply. Load variations of a power system are managed by fully exploiting market forces.

\section{Testing a new approach to preferential dispatch}

The scheduling and dispatch of power generating units is an important issue for the integration of variable renewables. As mentioned above, system operators in China employ a rule of even load scheduling - regardless of the energy sources (coal, hydro or hydro). Power generation technologies are allocated a more or less fixed number of operating hours to supply electricity to the grid.

When supply exceeds demand, the load is cut evenly across all technologies with exception of electricity coming from variable sources, which could be curtailed first. The curtailment is particularly evident when heat-generating plants must guarantee supply for district heating.

In 2007, the National Development and Reform Council (NDRC) launched a trial Regulation on Energy Conservation Power Generation Dispatching, which is still being tested in five provinces in China. The new rule divides and prioritises power generation technologies according to their efficiency merit order, as follows: 
- Wind, solar, ocean and (unadjustable) hydro

- Adjustable hydro, biomass, geothermal and solid waste

- Nuclear

- Coal-fired CHP units

Page | 20 - Natural gas and coal gasification-based combined cycle

- Other coal-fired units including co-generation without head load

- Oil-based generation units

In theory, the new rule gives preferential dispatching to renewables, thereby ensuring that as long as reliability and stability of supply is secured, they will run at their full capacity. Contrary to past practice, system operators would adjust production of the rest of the fleet accordingly.

Experience has shown that the trial order leads to insufficient operating hours of coal-fired plants or forces them to run at less than full load. This increases coal consumption and affects negatively the lifetime of coal-fired plants. It also affects the revenue of the utilities in the five provinces, which is directly linked to the number of hours their plants run per year.

Although there is no official report of how the trial has been implemented so far, unofficial sources indicated some local resistance to such a regulation. It is also known that discussions are underway to investigate a mechanism to provide financial compensation for owners of low merit order plants, as well as incentive plans to encourage utilities to retain some of their smaller units as ancillary reserves.

Although the trial rule does not explicitly allow it, system operators can override the merit order under certain local circumstances. Local grid operators can, for example, cite the security and reliability of electricity supply as valid reasons to curtail electricity from variable renewables. The situation might improve once a minimum intake of renewable electricity is determined by the NEA (more in the Policies and Standards section). 


\section{Demand-side management and storage}

\section{Demand-side management}

Demand-side management (DSM) or demand-side response is another option to increase flexibility in electricity consumption to accommodate the variable nature of renewable power generation. DSM is the planning, implementation, and monitoring of utility activities designed to encourage consumers to modify patterns of electricity usage, including the timing and level of electricity demand (EIA, 2010). DSM helps to reduce the operational costs of renewable integration through measures such as load shifting and peak shaving, which can reduce the need for a system operator to maintain costly ancillary services.

Smart grids ${ }^{3}$ can play an enabling role in DSM by allowing grid operators to record, control and to manage real-time electricity demand. By integrating advanced information technologies into the power system, smart grids enable operators to better manage generation, transmission and storage in ways that more effectively respond to system fluctuations in demand. In turn, smart grids help in load shifting, while maintaining the reliability and stability of the power system. The most innovative aspect of smart grids is that, through the installation of smart meters, they allow consumers to participate in demand response.

In OECD countries, the potential of smart grid is most closely linked to real-time management of electricity consumption and pricing. This makes it possible to use market forces to engage consumers in behavioural changes that help to shift demand from peak to off-peak hours.

China's residential sector consumed $12.5 \%$ of the total electricity produced in 2009. (For comparison, residential electricity consumption accounted for $36 \%$ of the total in the United States in 2008.) The proportion is relatively small but the demand variability tracks more closely the weather conditions. The fact that electricity consumption peaks in the summer suggests a correlation between residential electricity use (e.g. to power air conditioners) and peak demand, assuming that peak demand happens when peak consumption is recorded (Figure 9).

Figure 9. Monthly electricity consumption in China, 2008 and 2009

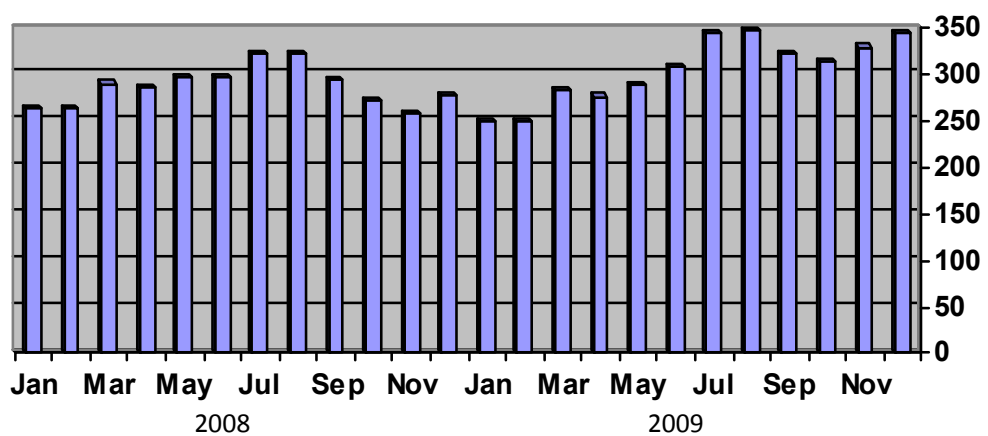

\begin{tabular}{|l|}
\hline Eectricity \\
consum ption \\
(TWh)
\end{tabular}

Source: Zhang, 2010

\footnotetext{
${ }^{3}$ A smart grid is an electricity network that uses digital technology to monitor and manage the transport of electricity from all generation sources to meet the varying electricity demands of end users. Such grids will be able to co-ordinate the needs and capabilities of all generators, grid operators, end users and electricity market stakeholders in such a way that it can optimise asset utilisation and operation. In the process, smart grids minimise costs and environmental impacts while maintaining system reliability, resilience and stability (IEA, 2010b).
} 
Industry holds the largest potential to implement DSM measures to respond to supply changes, typically by shaving or shifting peak load. Industry in China consumed $73.1 \%$ of the electricity produced in 2009, up 4.5\% compared with 2008 (Zhang, 2010). (In the United States, industry consumed only $24 \%$ of the total electricity generated in 2008). Although industry demand for electricity is far less variable over the course of each day or across the seasons, there are large margins to improve energy efficiency in industrial processes and implement energy-saving technologies.

DSM exists to some extent in China, but is still usually enforced by regulation at the provincial level. In Jiang Su province, for instance, the local government launched (in 2003) a scheme of differentiated peak and valley electricity prices for the residential sector. This measure has effectively encouraged people to consume electricity in off-peak hours. Similar pricing incentives (also agreed and implemented at the provincial level) are applied to industry to promote peak shaving and load shifting, along with measures to shut down energy-intensive factories to help rationalise electricity use in extreme weather conditions.

Nevertheless, differentiated electricity pricing is not a real-time measure. As the measure divides the day into two or three time intervals for which prices are fixed, it does not allow real-time response to demand-supply fluctuations across smaller time intervals, as might result from variable renewables.

\section{Electricity pricing}

Some countries such as Finland have adopted end-use, real-time pricing that allows both residential and industrial consumers to participate in demand response. In China, the complexity of electricity pricing could significantly constrain this dimension of DSM.

As electricity prices in China do not entirely reflect - or even track in real time - market prices, there is little opportunity for using price signals to motivate change. NDRC has the central role of price fixing, and on-grid or end-use prices are set months or a year ahead (Figure 10). As a result, China effectively has no electricity wholesale and spot markets. The absence of a real-time spot market between the grid companies and utilities means that utilities have no price incentive to start up or dispatch spare units during supply crunches. At the same time, consumers have low incentive to save electricity as electricity prices are heavily subsidised.

Figure 10. Electricity pricing mechanism in China

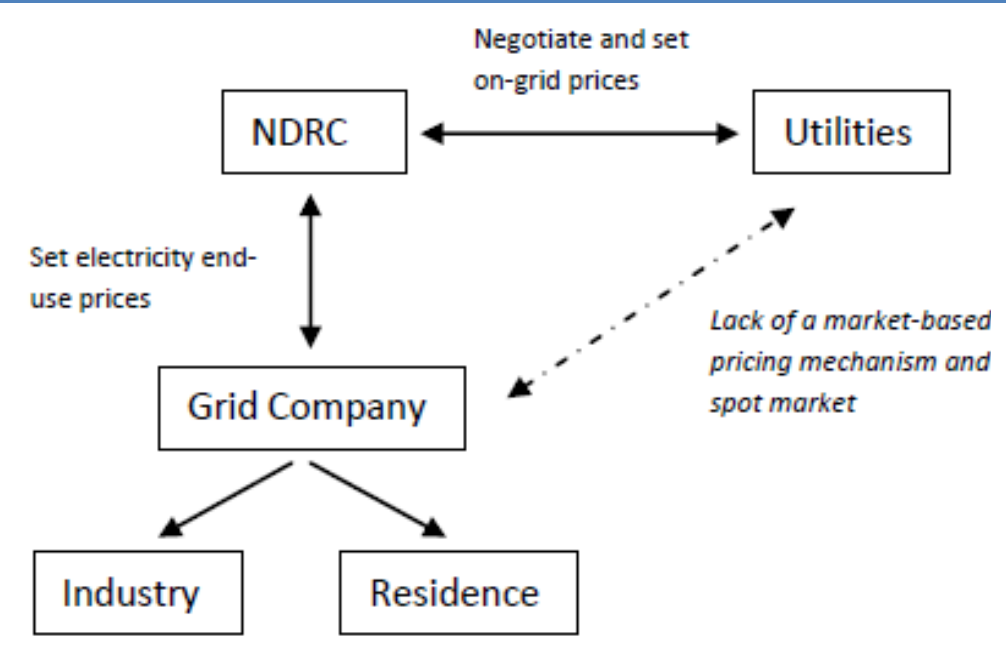

Residential electricity prices are agreed between the provincial NDRC and the grid companies, and are kept artificially low and stable to support social stability. As of 2007, the average electricity price for the residential sector was RMB $0.42 / \mathrm{kWh}$ (USD $0.064 / \mathrm{kWh}$ ), roughly $40 \%$ of 
the international average. Though still low, the average industrial electricity price in China, RMB 0.69/kWh (USD 0.105/kWh), is closer (70\%) to the international average (Huang, 2009).

On the generation side, on-grid prices vary by province, sector and technology. Prices for electricity from nuclear plants fed onto the grid are agreed individually by plant. For wind, the government established a feed-in tariff in 2009. On-grid prices that grid companies pay to wind farms depend on the richness of the province's wind resources, and range from RMB 0.51, 0.54, 0.58 to $0.61 / \mathrm{kWh}$ (USD 0.076, 0.08, 0.09 and $0.093 / \mathrm{kWh}$ ). The proposed prices are higher than those for coal-fired plant which stand at an average of RMB 0.35/kWh (USD 0.05/kWh).

The disconnect between pricing and demand in China is most evident for coal-fired power generation. While domestic coal prices are gradually catching up with international markets, electricity prices are kept low by the government; this often forces utilities to incur considerable losses.

Electricity pricing is a powerful fiscal tool by which the central government can control inflation and sustain economic growth. Electricity is considered a basic commodity, and prices must be kept at a stable and affordable level. The NDRC allows limited price fluctuation with, for example, the entry into force of a peak-valley pricing system. But real-time price response to supply fluctuations is not a foreseeable option at present or in the near future.

Hence, the functionality of a smart meter in China leans more towards its primary ability to enable system operators to measure real-time electricity consumption - and in turn directly or indirectly manage demand. Some smart meter pilot programmes have started in China (Box 5).

Box 5. Pilot smart meter programmes in China

General Electric Corporation, a US multinational company, recently opened a smart grid demonstration centre in the city of Yangzhou. The initiative aims to promote energy saving through smart meters and home energy management systems, programmable thermostats and smart electric appliances. Home-based charging stations for plug-in hybrid electric vehicles (PHEVs) will also be tested. Other smart grid demonstration projects include the SGCC-sponsored eco-city project in Tianjin, launched in early 2010, which features an intelligent transmission and distribution system, and aims to provide more than $20 \%$ of the electricity from renewable sources (ECO CITY, 2010).

\section{Electricity storage}

The role of electricity storage becomes prominent when large shares of variable renewables penetrate the power mix. Electricity storage technologies can be applied to meet short- and longterm load variations, with its capacities varying from less than $1 \mathrm{~kW}$ to $1 \mathrm{GW}$ (IEA DSM, 2010). Various technologies exist or are on track to be developed, such as pumped hydro plants and lithium batteries, etc. The Chinese government's preference leans more towards large-scale storage capacity, i.e. pumped hydro plants and potentially electric vehicles (EVs).

Pumped hydro plants store electricity by pumping water to the upper reservoir in off-peak hours for release when needed, thereby providing also a means of mitigating load variations. Compared with other storage options such as flow or lithium batteries, pumped hydro is the most economic. The production cost of flow batteries in China is currently about RMB $25000 / \mathrm{kW}$ (USD 3 800/kW); that of lithium batteries is RMB $10000 / \mathrm{kW}$ (USD $1500 / \mathrm{kW}$ ). In contrast, the production cost of pumped hydro stands at around RMB $3000 / \mathrm{kW}$ to RMB $4000 / \mathrm{kW}$ (USD 460/kW to USD 610/kW) (China Energy News, 2010b). 
The electrification of transportation and the role of EVs in power demand volatility and in mitigating power fluctuations are still an open question, but many countries are testing the concept's viability. If managed effectively, EVs can serve as both storage and dispatchable energy resources. Connected vehicle batteries can provide temporary storage capacity for electricity surplus, which can later be released to balance power fluctuations. The potential of EVs will grow considerably when they reach a meaningful share of the vehicle market.

In China, EVs are now being introduced and subsidised in 10 selected cities. In the New Energy Automobile Development Plan currently being drafted by the Chinese Ministry of Industry and Information Technology, the stock of EVs (including plug-in, pure electric and hydrogen-fuelled vehicles) should reach five million by 2020 , and potentially much more by 2030 . The plan will start with public transport and gradually expand into private vehicles.

In parallel, the Ministry of Science and Technology (MOST) is co-ordinating the standardisation of nationwide vehicle charging facilities. Battery technology should improve and costs become more competitive when production levels increase as technology learning takes hold. Once integrated into the power system, the five million EVs could potentially contribute to the balancing of electricity generation and consumption of the local grids. The roll-out of EVs, however, requires the government action in three areas: to invest in and obtain technical breakthroughs (e.g. grid-to-vehicle, vehicle-to-grid, battery durability); to develop infrastructure (e.g. urban planning, distribution grids and load management); and to establish incentive policies to shape consumer behaviour. 


\section{Policies and standards}

\section{Policies}

To its credit, the government of China has put in place favourable policy and legislation that contribute to the fast growth of renewables. The Renewable Energy Law (2005) remains the most relevant to overall integration. Under this law, power grid operators are requested to "buy all the grid connected power produced with renewable energy within the coverage of their power grid, and provide grid-connection service for the generation of power with renewable energy". This should be achieved through grid connection agreements between grid operators and renewable power generation companies.

In reality, implementation of this specific clause has been inconsistent. When local grids are saturated, and cannot accommodate all the incoming electricity or easily transmit the electricity surplus through to adjacent grids, grid companies typically curtail electricity generated by wind farms. This reflects the fact that on-grid prices for coal-fired plants are cheaper than those for wind; as result, variable and more expensive wind power loses ground to the cheaper and more reliable electricity from coal plants. In addition to paying out more to bring wind power onto the grid, grid companies are forced to shoulder part of the costs of physically connecting the wind farms. Obviously, they have little incentive to integrate power sources that increase unpredictability and net variability of their power systems.

In Inner Mongolia, the speed and magnitude of mega wind farm construction leave little time for the grid to react to the sudden influx of variable electricity from one year to another. It is estimated that the total installed capacity was set to double again over the course of 2010 pending on the release of official data. Insufficient inter-regional grid connection causes a substantial wind-power bottleneck.

In view of such difficulties, a revised Renewable Energy Law took effect in April 2010. The revised law now "obliges" grid companies to guarantee the purchase of a minimum amount of electricity from renewable energy. The details of how this obligation can be achieved and what percentage of electricity from renewables is mandatory are still to be determined.

\section{Standardisation}

Many government-induced policies and initiatives helped accelerate the development of China's renewable industry. Several concession programmes, in both wind and solar, have been launched to stimulate the growth of the industry. Wind farm developers rushed to occupy some of the best locations and often offer competitive bidding prices for wind projects. In 2010, the investment cost of a 1.5 MW wind turbine fell by more than half, to less than RMB 4 000/kW (USD 605/kW).

The hasty expansion of wind capacity has, however, ignored some important technical elements. Almost none of the wind plants installed have the ability of low voltage ride-through (LVRT). When the wind generation capacity is low, the variability of wind power generation can be absorbed rather easily by load variation. When a larger quantity of variable renewables is connected to the grids, it could put the stability of the power system in risk. At least two measures can be taken to improve the grid-friendliness of renewables:

- Setting grid codes;

- Instituting a wind forecasting system for grid-connected wind plants. 
The NEA started a round of consultations in March 2010 to inform guidelines on Standards on Wind Farm Connection. Active power control systems, reactive power compensation devices and LVRT capabilities are among the requirements suggested. The draft standards are seen by the industry as stringent, and would require developers and turbine suppliers to upgrade their equipment (BNEF, 2010b). Industry insiders predict that the new standards could favour a few large wind power manufacturers and drive out smaller competitors. Fierce competition and frequent curtailment have already driven down the profit margins of many wind-farm developers. Tightening of the standards may - or may need to - be accompanied by some form of compensation from the government.

The draft standards also suggest the implementation of a wind forecasting system, which sends forecasts 48 hours ahead, as well as close to real-time forecasts of 15 minutes to four hours ahead. Data will be sent to local system operators. Shorter-term and more accurate forecasts can significantly help system operators in scheduling the dispatch of ancillary units and hence in reducing the integration costs of variable renewables.

The timing of the standards coincides with the forthcoming obligatory minimum percentage of renewable intake in the revised Renewable Energy Law. In the defence of grid companies, integrating variable renewables has an impact on the power quality, and therefore should be managed through better technical standards and more accurate forecast of electricity generation from renewables. In the long run, standards are indispensable for accommodating a much higher amount of variable renewables in the power system. 


\section{Conclusion}

The challenge of integrating variable renewables is not unique to China; it is also evident in many developed or emerging countries. The Chinese government's top-down centralised planning approach, which stimulated the rapid growth of renewable energies, applies now to address the integration of renewables. China is moving rapidly and on all fronts: generation, transmission, interconnections, storage and demand-side management. Smart grids could be a means linking all the elements along the chain.

Table 2. Summary of ongoing initiatives

\begin{tabular}{|l|l|}
\hline Generation & $\begin{array}{l}\text { Building more flexibility in the generation mix e.g. adding hydro, gas and } \\
\text { pumped hydro stations. }\end{array}$ \\
\hline Transmission & $\begin{array}{l}\text { Building cross-region UHV lines to expand balancing area and potentially form } \\
\text { a national grid. }\end{array}$ \\
\hline Interconnection & Strengthening the receiving end by connecting regional grids. \\
\hline DSM & $\begin{array}{l}\text { Developing options such as EVs; and wider implementation of peak-valley } \\
\text { electricity pricing, and demonstrating smart grids. }\end{array}$ \\
\hline Storage & Adding storage options such as pumped hydro and potentially EVs. \\
\hline Policies and Standards & $\begin{array}{l}\text { Setting targets and national technical standards. } \\
\text { Revising and implementing Renewable Energy Law. } \\
\text { Moving towards more dynamic electricity pricing (DSM Measures) and } \\
\text { preferential dispatching. }\end{array}$ \\
\hline
\end{tabular}

However, capacity aside, market is the key. A quick summation of some of the inherent characteristics of China's electricity market shows the need for more radical solutions to support greater penetration of variable renewables:

- Diminishing numbers of smaller plants mean that system operators will rely more on big coal plants for balancing.

- Independent management of three grid companies creates low incentive for these companies to solve transmission cross-border bottlenecks.

- Fixed on-grid and end-use electricity prices mean there is no spot market and hence little incentive for utilities to release spare capacity or to maintain ancillary service units.

- Long-term contracts for electricity trading among regions and provinces mean that both tradable amount and prices are fixed a year ahead; there is no price incentive for system operators to accommodate imports.

The rigidity of the structure and design of China's electricity market runs counter to the kind of flexibility that a power system needs exactly to incorporate higher shares of variable renewables. The central government's tight grip on pricing is a key challenge that could undermine its own efforts to enlarge the country's transmission and flexible generation capacity. Measures undertaken are usually heavily administrative: change is driven by target-setting rather than market forces. Yet clear targets set by the Chinese government give the market and industry long-term confidence and certainty that renewables will continue to grow, and that all solutions that contribute to the integration of renewables are on the table. 
What is essential to the deployment of renewables is for the government to have a long-term view on the development of key technologies and strategic planning of major infrastructures, especially the grid planning. This requires a vision beyond the heavily focused Five-Year Plans and beyond 2020. In the mean time, the electricity power market must evolve gradually.

Page | 28 on a China 2050 Wind and Grid Integration Roadmap. The co-operation aims to support China's policy makers by providing a long-term scenario for wind power development, taking into account the important factor of power system integration and the various challenges described in this paper. 


\section{References}

ADB (Asian Development Bank) (2010), Asian Development Outlook 2010, Asian Development Bank.

BNEF (Bloomberg New Energy Finance) (2010a), “China's $12^{\text {th }}$ Five-Year Plan and Seven Strategic Emerging Industries: A Preview", Bloomberg New Energy Finance, 8 November 2010.

BNEF (2010b), "Lost in Transmission: China Wind's Grid Bottleneck", Bloomberg New Energy Finance, 6 September 2010.

CEC (China Electricity Council) (2010), National Electric Power Industry Statistics 2009 Express, January 2010, China Electricity Council.

Chandler, H. (2009), Empowering Variable Renewables - Options for Flexible Electricity Systems, OECD/IEA, Paris.

Chang, J., and Dayu, C. (2010), Analysis on a 'Flexible' Inter-provincial Long-term Contract of Electricity Trading, State Electricity Regulatory Commission of China, September 2010.

China Energy News (2010a), "National Planning and Investment of UHV Transmission Grids Released", China Energy News, 13 August 2010.

China Energy News (2010b), "Pumped Hydro Storage is the Optimum Option for Large-scale Renewable Development", www.cnenergy.org/_d271194614.htm, China Energy News, 28 January 2011.

CMA (China Meteorological Administration) (2010), Results of the National Wind Resources Survey, China Meteorological Administration, 5 January 2010, www.cma.gov.cn/mtjj/201001/t20100105_55807.html.

CSG (China Southern Grid Corporation) (2005), Enhance Demand-side Management According to Local Cconditions, China Southern Grid Corporation, June 2005.

CWEA (China Wind Energy Association) (2010), Outlines Prepared by CWEA for the China 2050 Wind and Grid Integration Roadmap, China Wind Energy Association, November 2010.

ECO CITY (2010), Sino-Singapore Tianjin Eco City, www.eco-city.gov.cn/eco/shouye/main.html.

EEO (2010), "Wind Power in Western Inner Mongolia: Benefit from and Restricted by its Independence", EEO Online, 22 June 2010 www.eeo.com.cn/industry/energy_chem_materials/2010/06/21/173281.shtml.

EIA (Energy Information Administration of the United States of America) (2010), Energy Glossary, www.eia.doe.gov/glossary/index.cfm?id=D, 2010.

ENTSOE (European Network of Transmission System Operators for Electricity) (2010), Impact of Increased Amounts of Renewable Energy on Nordic Power System Operator, European Network of Transmission System Operators for Electricity (ENTSOE), 31 August 2010.

FT (2010), “China beats the US in Wind Energy”, Financial Times, 25 January 2011.

GWEC (Global Wind Energy Council) (2009), Global Wind Report 2009, Global Wind Energy Council.

GOC (Government of China) (2010), Electricity Demand Side Management Measures, Central Government of People's Republic of China, 16 November 2010.

Huang, S. (2009), Review and Outlook of Electricity Pricing in China, State Electricity Regulatory Commission, www.chinapower.com.cn/articleattachment/1160/art1160012.pdf, August 2009. 
IEA (International Energy Agency) (2009), World Energy Outlook 2009, OECD/IEA, Paris.

IEA (2010a), World Energy Outlook 2010, OECD/IEA, Paris.

IEA (2010b), Energy Technology Perspective 2010, OECD/IEA, Paris.

IEA DSM (IEA Implementing Agreement on Demand-Side Management) (2010), Integration of Demand-Side Management, Distributed Generation, Renewable Energy Sources and Energy Storages V1, IEA Implementing Agreement on Demand-Side Management, 2010.

IEA RETD (IEA Implementing Agreement on Renewable Energy Technology Deployment) (2010), Policy Makers Report: Opportunities for the Use of Renewable Energy in Road Transport, IEA Implementing Agreement on Renewable Energy Technology Deployment, March 2010.

Inage, S. (2009), "Prospects for large-scale energy storage in decarbonised power grids", IEA Working Paper, OECD/IEA, Paris.

Interfax China (2010), China Becomes World's Largest Wind Power Generator, Interfax China, 17 January 2011.

Mi, J. (2010), Upon Power Efficiency in China, presented at Joint IEA-India Workshop on Industrial Energy Efficiency, China Electricity Council, 27 January 2010.

MIIT (Chinese Ministry of Industry and Information Technology) (2010), National Power industry statistics 2009, Chinese Ministry of Industry and Information Technology, press release, 7 January 2010.

Minchener, A. (2010), Developments in China's Coal-fired Power Sector, IEA Clean Coal Centre January 2010.

NBS (National Bureau of Statistics) (2010), Statistical Communique on the 2009 National and Economic and Social Development, National Bureau of Statistics, February 2010.

Porter, K. (2010), Calculating Reserve Needs and Costs in Wind Integration Studies: A Review presentation prepared for The Energy Foundation: China Sustainable Energy Program, 2 September 2010.

Porter, K., C. Mudd, S. Fink, J. DeCesaro and R. Wiser (2009), A Review of Large-scale Wind Grid Integration in the United States, The Energy Foundation: China Sustainable Energy Program, June 2009.

SGCC (State Grid Corporation of China) (2010), Economic Comparison between Power Transmission by UHV and HV Grids, www.sgcc.com.cn/ztzl/tgyzl/tgyzs/226408.shtml, State Grid Corporation of China.

SGERI (State Grid Energy Research Institute) (2010a), Outlines prepared by SGERI for the China 2050 Wind and Grid Integration Roadmap, November 2010, State Grid Energy Research Institute.

SGERI (2010b), China Electricity Supply/demand and Development of Energy Sources 2010, State Grid Energy Research Institute.

Topcj (2010), "Pumped hydro and hydro stations are to go beyond expectation", Top Caijin, 7 July 2010.

Wang, Z. (2009), Market potential and technology transfer, NDRC Energy Research Institute, 9 November 2009.

Zhang, G. (2010), Report on China's Energy Development 2010, China's National Energy Administration. 


\section{iea}

\section{International Energy Agency}
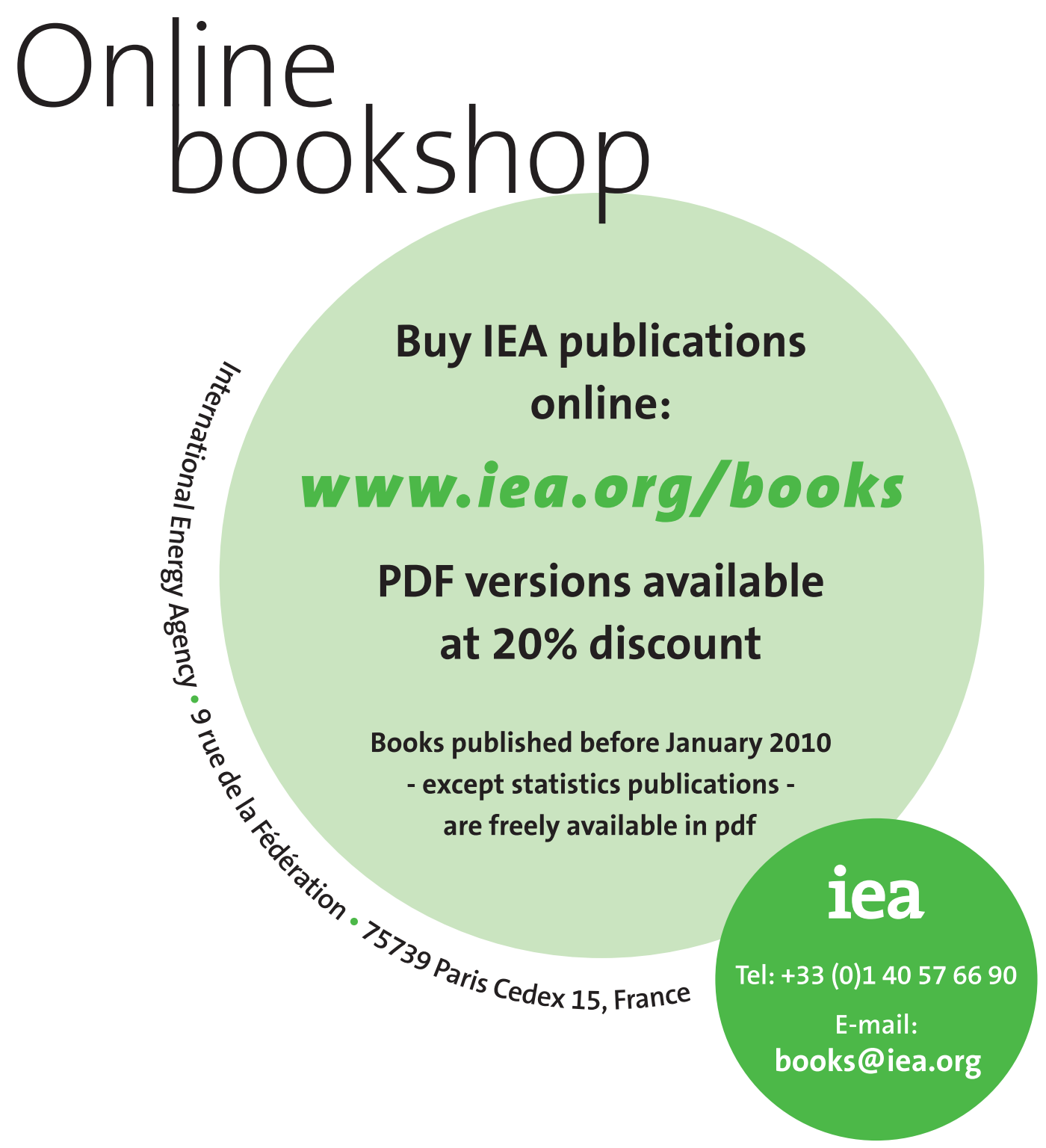


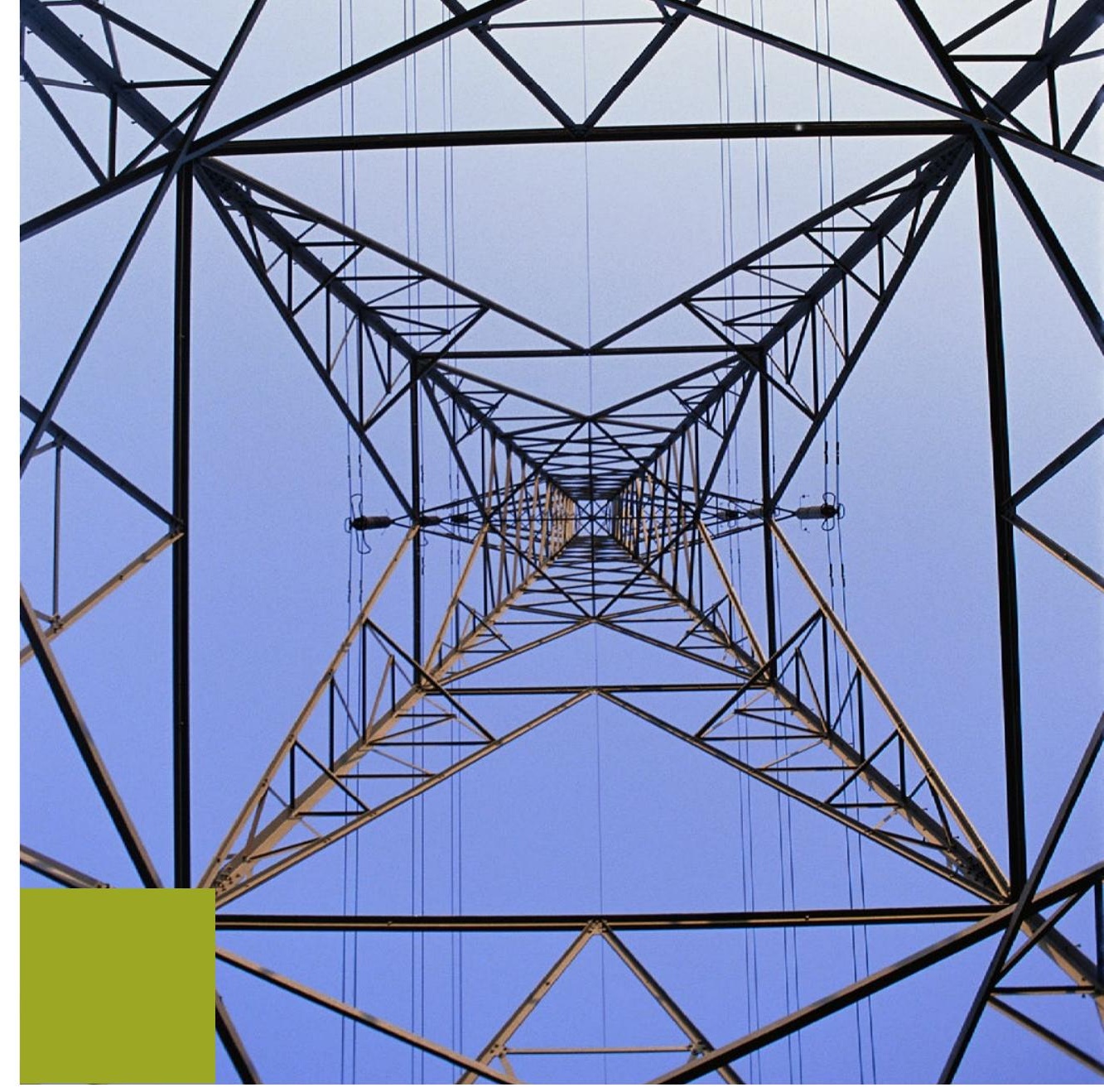

International Energy Agency

9 RUE de LA FÉdÉRATION 75739 Paris Cedex 15 